\title{
Attachment, Aggression and Victimization among Adolescents
}

\author{
NainaKunchal ${ }^{\beta}$, NandiniSanyal*${ }^{\dagger}$, Saher Ali***, Tina Fernandes** \\ St. Francis College for Women
}

\author{
*Asst. Prof., Dept. of Psychology, St. Francis College for Women, Begumpet, Hyderabad - 500016. \\ **Head, Dept. of Psychology, St. Francis College for Women, Begumpet, Hyderabad - 500016. \\ *** Lecturer, Dept. of Psychology, St. Francis College for Women, Begumpet, Hyderabad - 500016. \\ ${ }^{\beta}$ Graduate Student, St. Francis College for Women, Begumpet, Hyderabad - 500016
}

${ }^{+}$Direct All Correspondences To: NandiniSanyal

\begin{abstract}
The objective of the present study is to determine if there is a relationship between attachment, proactive-reactive aggression and peer victimization among middle (aged between 13-15 years) and late adolescent (aged between 16-18 years) boys and girls. A non-probabilitypurposive sampling method was used to select asample $(\mathrm{N}=195)$ from different schools in Hyderabad. The Inventory of Parent Peer Attachment (Armsden\& Greenberg, 1987), Reactive-Proactive Aggression Questionnaire (Dodge \&Coie, 1987) and Multidimensional Peer Victimization Scale (Mynard\& Joseph, 2000) were administered to measure attachment, aggression and victimization respectively. Significant gender differences were found in adolescents with respect to the dimensions of aggression and victimization $(p<0.05)$. However, no significant differences were found in the developmental stage with respect to attachment, aggression and victimization. The study also found significant correlations between peer attachment, aggression and victimization $(\mathrm{p}<0.05)$. This study highlights the importance of helping adolescents increase their capabilities of adjusting emotions to a desired state and level of intensity and encourage them to engage in strategies to regulate negative emotions.
\end{abstract}

Keywords: adolescents, attachment, peer victimization, proactive -reactive aggression

\section{INTRODUCTION}

Adolescence can be described as a period of transition in which an individual progresses towards adulthood from childhood (Smith, Cowie \& Blades, 2003), generally beginning at 11 years of age and lasting through teenage years. It is not only a period of transition but also a period of rapid growth, development and change. The change can be seen in biological as well as psychological aspects. Biological changes are seen through the onset of puberty and development of secondary sexual characters and the various hormonal changes while psychological changes can be seen in the form of development of an identity and personality, understanding gender roles, progressing towards social independence.During these developmental years, adolescents face many difficulties due the biological and psychological changes that their bodies undergo. These difficulties were explored by various personality theorists, for example Hall (1904) suggests that adolescence can be called a period of "storm and stress" due to the various hormonal changes that occur in the body, while Erik Erikson (1968) suggests that difficulties rises due to the conflict between their own identity and the roles they are expected to play (identity v/s identity confusion).

Adolescence is not only a difficult period for adolescents but also a difficult period for parents. Corresponding to the psychological and biological changes, are the changes in dynamics and functioning of the family (Kulaksızoğlu, 1998) and family relations which cause family conflicts and which lead to "estrangement" from parents and family (Dincel,2006) and more attachment towards peers and establishment of new peer relations which are extensions of attachment and bonds formed during infancy. This advancement could be better understood with the help of Bowlby's attachment theory. Bowlby (1982) defines attachment as one the "specific and circumscribed aspect of the relationship between a child and caregiver that is involved with making the child safe, secure and protected."

Bowlby (1988) suggested that when the children develop a secure attachment to their primary caregiver, they develop an internal working model and sense of self that serves as guide for social interaction and contribute to positive experiences in their relationship with other. The basic premise of attachment theory is that the quality of attachment relationship that stems from interaction between infant and their caregiver, particularly the degree to which they can rely on attachment figure for security and support. Caregivers (especially mother) who are sensitive and consistently responsive to their infant's needs are likely to foster secure attachment in their children. 
Attachment is not only important for guidance and establishment of new relations, but also plays an integral role in facing developmental challenges during adolescence.Aken, Buist, Dekovic\&Meeus (2004) suggest that parental attachment is directly linked with psychological well-being and adjustment among adolescents and contributes to positive aspects (such as self-esteem and life satisfaction) and negative aspects (such as depression and anxiety) of well-being (Armsden\& Greenberg,1987). The nature and quality of the attachment this parent child interaction also contributes to development of social relationship, emotional regulation and coping mechanism (Sroufe, Carlson, Levy \&Egeland, 1999).

As children grow towards maturity, they progressively seek the company of their peers, seemingly integrating the behaviors of their peers into their present internal working models, based on their earlier attachments to parents (Hazan\& Shaver, 1994). This process helps us understand the manner in which parent and peer interactions may correlate, leading to the formation of more generalized working models, which influencestheindividuals' resulting adaptation (Lieberman, Doyle, \&Markiewicz, 1999). However, according to Perry (1996) if the nature of the establishment of these relations is emotional and insecure it may result in behavioral problems at latter stages of life. Research suggests that insecurely attached children exhibited more aggressive and violent behaviour.

Aggression, as defined by the Oxford Dictionary of Psychology (2009) as behavior whose sole purpose is to injure another person physically or psychologically. Aggression may manifest itself in many ways may take various forms such as social and verbal aggression, physical aggression and more serious kinds of violence. Physical aggression includes behaviors that are directed towards inflicting physical harm and commit violent crimes such as "robbery, rape and homicide (Karriker-Jaffe, Foshee, Ennett, \&Suchindran, 2008). Contrary to physical aggression is , social aggression which "encompasses various forms of non-physical aggression" .Socially aggressive behaviors are directed and focused on damaging and threating social relations rather than causing physical harm (Archer \& Coyne, 2005).Examples of socially aggressive behaviors include "gossiping" (Xie, Swift, Cairns, \& Cairns, 2002), "excluding or alienating" a person from a group and social situations, and an attempt to cause harm to an individual's social standing in a group (Crick \&Grotpeter, 1995).

Various parental factors such as "parental maltreatment" (Cullerton-Sen et al., 2008) and the degree to which parents exercise control over the children determines the nature of aggressive behavior. For instance adolescents who are imposed with physical punishment or control are likely to be physical aggressors while ones imposed with psychological control are likely to become relational aggressors (Kuppens, Grietens, Onghena, \&Michiels, 2009). Aggressive behaviourmay also be results of situations that stimulate shame, anger and blame(Baumeister, Smart, \& Boden,1996), aresult of misinterpretation of social cues and other factors such as the difference in processing social information (Camodeca et al, 2003). "Self-perceived popularity" can be considered as another feature linked with aggression (Mayeux\&Cillessen, 2008). Students who perceive themselves as being popular engage in aggressive behavior more than their peers. However, students who perceive themselves as being disliked are also more likely than their peers to engage in aggressive behaviors. Even association with aggressive and perceived popular peers is linked to being seen as a bully (Estell et al., 2009). According to ecological perspective (Espelage\& Swearer, 2002) aggressive behaviours are based on the interactions between the "psychological" and "individual characteristics" of both the aggressor and the victim and therefore lays stress on domains such as "family, community and school climate". (Barbozaet al., 2009; Bronfenbrenner \& Morris 1998; Limber, 2006).

Aggressive behavior may be problematic both for those who behave aggressively i.e., bullies, and for those who become victims of this aggressive behavior. Aggressive behaviors in childhood are associated with several problems such as peer rejection and hyperactivity (Coie\& Dodge, 1998; Parke \&Slaby, 1983). These behavioursalso predict adjustment problems such as delinquency, substance use and absenteeism during the later stages (Parker \& Asher, 1987). Aggressive behaviors are complex and multidimensional, which may cause difficulties and confusion in our understanding of how these processes develop, emergence and maintained as well as our understanding of the impact of these behaviors have on social relationships. Accordingly, researchers have stressed on the importance understanding the differences among these peculiar forms of aggressive behaviors. For instance, Dodge and Coie (1987) proposed a distinction between the two forms of aggression:reactive aggression and proactive aggression. They defined proactive aggression as an aggressive goal directed behavior aimed at reaching a desired outcome whereas reactive aggression is the act displaying hostile behaviors as a result of a perceived threat or danger (Dodge \&Coie, 1987). According to Tuvblad et al. (2009), bullying can be characterized as a result of either reactive or proactive aggression or both.

Andreou (2001) places children involved with bullying into one of three categories: bullies, victims, or bully-victims (Andreou, 2001). Bully-victims can be described as those individual who are involved in bullying and also experience victimization. Hawker and Boulton (2000) define peer victimization as "experience of being a target of a peer's hurtful teasing and aggressive behaviors'. Peer-victimization can be either direct or indirect. Direct forms of victimization can be defined as open provocative attacks whereas indirect forms of victimization can be understood as covert attempts of manipulation. Evidence suggests that direct victimization is more likely 
to be experienced by boys, whereas indirect victimization is more likely to be experienced by girls (Bjorkqvist et al., 1992; Crick\&Grotpeter, 1995, Olweus, 1985, 1993; Whitney \& Smith, 1993). Peer victimization can result in devastating consequences for children and adolescents. Evidence accumulated suggests that indirect victimization is more harmful than direct victimization (Crick \&Bigbee, 1998; Hawker \&Boulton, 1997).

Research conducted previously also associated peer victimization to internalizing symptoms like emotional dysregulation (McLaughlin et al., 2009) anxiety and loneliness (Bellmore, Witkow, Graham, \& Juvonen, 2004), not only is peer victimization related tointernalization of symptoms but it also reduces life satisfaction among the aggressors as well as the victims. (Flaspohler, Elfstrom, Vanderzee, Sink, \&Birchmeier, 2009). However, support from teachers, peers and family may reduce this association. Peer victimization is related to school difficulties as well (Thijs \&Verkuyten, 2008), as victimized children tend to have a "lower sense of selfefficacy" and their academic achievement also tends to be lower than their peers. Additionally, absenteeism can be observed more in victimized children than their peers (Gastic, 2008). Interestingly, victims are also more likely to get into trouble at school and more likely to receive serious forms of discipline than non-bullied children. These difficulties often result in school transfers. One of the most devastating consequences of bullying is the higher incidence of suicide attempts and ideation among bullies, victims, bully-victims, and even bystanders (Klomek, Sourander\& Gould, 2010).

Jeynes(2008) found that role of parental involvement can be linked to both aggression as well as victimization. In a study conducted by Finnegan, Hodges, \&Perry(1998) they found that the incidence of victimization was higher in children with less involved parents than the children with more involved parents. They also concluded that besidesparental involvement, mother-child relations are also associated to peer victimization. However, Beran (2009) found gender differences with respect to this relationship. He suggested that victimization in boys can be associated related to "perceived maternal over-protectiveness"whereas victimization among girls can be related to "perceived maternal rejection". This is especially the case when boys react with fear during mother-child conflicts and girls cope aggressively during mother-child conflicts. Not only arematernal relationships linked to peer victimization but also parental relationships, particularly the rejecting and dysfunctional attitudes of the fathers. In a study conducted by Gibb, Abramson, and Alloy (2004) on bullies it was found that emotional ill treatment by the parents was more likely to be experienced more by the bullied children than non-bullied children.

The importance of parental and peer attachment and its association with various positive factors (such as individuation, life satisfaction, high self-esteem etc) and negative factors (depression, anxiety, peer rejection etc) are extensively supported by the large body of existing literature. However there is no evidence of empirical data available that associates proactive and reactive aggression with attachment among adolescents. The study of proactive and reactive aggression has been limited to the context of bullying. The researcher explores the following questions with the help of the present study

- Do middle and late adolescent boys and girls differ in terms of attachment, aggression and peer victimization?

- Is there is a relationship between attachment, aggression and peer victimization in middle and late adolescents?

\section{OBJECTIVES}

1. To determine if there is a role of developmental stage (viz., middle adolescence and late adolescence) and gender(boys and girls)of adolescents on attachment (3 dimensions, viz., maternal, paternal and peer attachment), aggression (2 dimensions, viz., proactive and reactiveaggression) and peer victimization (4 dimensions, viz., physical victimization, verbal victimization, social manipulation, attack on property).

2. To determine if there is a relationship between attachment ( 3 dimensions, viz., maternal, paternal and peer attachment), aggression (2 dimensions, viz., proactive and reactive aggression) and peer victimization (4 dimensions, viz., physical victimization, verbal victimization, social manipulation, attack on property) in middle and late adolescents.

\section{Research Design}

\section{METHOD}

A between-groups design was adopted to determine whether there are any gender differences in middle and late adolescents with respect to attachment and its 3 dimensions (viz., maternal attachment, paternal attachment and peer attachment), aggression and its 2 dimensions (viz., proactive and reactive aggression) and victimization experiences and its 4 dimensions (viz., physical, verbal, social manipulation and attack on property). The study also adopts a correlational design to determine whether there is any correlation between attachment, aggression and peer victimization in middle and late adolescents. 


\section{SAMPLE}

A non-probability sampling technique was used to select a sample of 195 Adolescents. Out of the total sample, there were 111 middle adolescents ( 55 boys and 56 girls) and 84 late adolescents ( 43 boys and 41 girls). Adolescents aged between 13-18 years who had at least one sibling and who were living with their families were included in this sample.

\section{INSTRUMENTS}

Four questionnaires were used in this study, they were:

\section{- Information Schedule}

Participants were asked to provide details regarding their gender, age, relationship status of parents and history of any psychological disorder and the like in the information schedule.

\section{- Inventory of Parent and Peer Attachment (IPPA)}

Inventory of Parent and Peer Attachment (IPPA) developed by Armsden and Greenberg (1987) was devised to study the dimensions of relationships of adolescents with their parents, close friends and "how they serve as sources of psychological security". It is based on the theoretical framework of attachment which was originally formulated by Bowlby. The questionnaire is a self-report questionnaire which is a five point Likert scale. The original version consists of 53 questions (28 for parents and 25 for peers) yielding two attachment scores. However the present study uses the revised version and the questionnaire is divided into three parts, each consisting of 25 questions yielding three attachment scores in terms of psychological security. The first part asks questions related to mother or mother-like figure, the second asks about the father or father-like figure and the third asks about close friends. IPPA is scored by reverse scoring the negatively worded items and by summing up the scores in the each section. Thecronbach's alpha is 0.87 for maternal attachment, 0.89 for paternal attachment and 0.92 for peer attachment.

\section{- $\quad$ Proactive-Reactive Aggression Questionnaire (RPQ)}

Proactive-Reactive Aggression Questionnaire (RPQ) was developed by Dodge and Coie (1987). As the name suggests RPQ studies the two dimensions of aggression i.e., proactive and reactive aggression. It is a selfreport questionnaire, consisting of 23 questions of which 12 questions enquire about proactive aggression and 11 questions about reactive aggression. For each scale the participant has indicated how often they have engaged in each kind of behavior, ranging from 0 (not at all) to 2(more than once).The internal reliability for the two dimensions is .80 and .90 respectively.

\section{- $\quad$ Multidimensional Peer Victimization Scale}

Multidimensional Peer Victimization scale was developed by Mynard and Joseph (2000).It studies four dimensions of victimization: physical, verbal, social manipulation and attack on property. It is a self-report questionnaire consisting of 45 questions, however only 16 question have been used in this study. The participant indicates how often they were subject to victimization in the last school year responses ranging from 0 (not at all) to 2 (more than once).Higher scores reflect more victimization.Internal reliability for the subscales is 0.85 , $0.75,0.77$ and 0.73 respectively.

\section{PROCEDURE}

After the selection of the measures, the questionnaires and the Information Schedule along with a Consent form were prepared, organized and compiled together. The researcher made some arrangements to meet the authorities of different schools to seek permission for data collection. The researcher then visited the schools and colleges that gave permission on the scheduled dates under the supervision of the institution. A healthy rapport was built with the participants and they were made aware of the fact that their participation in the study is purely voluntary and complete confidentiality would be maintained throughout the study. The students who agreed to participate in the study were requested to sign the Informed Consent Form.Next, the Information Schedule was administered. The participants who met the sampling criteria were screened. On the next appointment the instructions for the questionnaires (namely, the IPPA, the RPQ AND MPVS) were given and the participants were requested to respond to the items. There was no fixed time limit for any of the questionnaires. However, the respondents were asked to complete each questionnaire in about 40 minutes. 


\section{RESULTS}

Table 1 - Results of Two-Way ANOVA and descriptive statistics with developmental stage and gender as the IVs and the 3 dimensions of attachment, 2 dimensions of aggression and 4 dimensions of peer victimization as the DV's.

\begin{tabular}{|c|c|c|c|c|c|c|c|}
\hline & \multicolumn{3}{|c|}{ Developmental Stage } & & & \multicolumn{2}{|c|}{ Developmental stage } \\
\hline & Middle Adolescence & Late Adolescence & & Boys & Girls & & $x$ Gender \\
\hline & $\operatorname{Mean}(\mathrm{SD})$ & $\operatorname{Mean}(S D)$ & $\mathrm{F}$ & $\operatorname{Mean}(S D)$ & $\operatorname{Mean}(S D)$ & $\mathrm{F}$ & $\mathrm{F}$ \\
\hline Maternal Attachment & $87.17(11.73)$ & 84.69(11.46) & 2.337 & $87.10(9.70)$ & $85.09(13.31)$ & 2.261 & 3.87 \\
\hline Paternal Attachment & $83.55(9.47)$ & $82.30(11.21)$ & .753 & $84.06(9.43)$ & $81.96(10.97)$ & 2.123 & 0.06 \\
\hline Peer Attachment & $89.45(11.31)$ & $88.32(11.57)$ & .440 & $87.76(12.61)$ & $90.18(9.96)$ & 2.093 & 0.00 \\
\hline Reactive Aggression & $13.00(5.66)$ & $11.82(5.32)$ & 2.330 & 13.31(5.95) & $11.65(4.96)$ & $4.61^{*}$ & 0.06 \\
\hline Proactive Aggression & $6.01(5.44)$ & $6.32(5.10)$ & .122 & $7.36(5.91)$ & $4.91(4.24)$ & $10.92^{* *}$ & 0.07 \\
\hline Physical Victimization & $1.53(1.89)$ & $1.65(2.28)$ & .132 & $2.15(2.33)$ & $1.01(1.57)$ & $15.44^{* *}$ & 0.03 \\
\hline Verbal Victimization & $4.40(2.07)$ & $4.15(2.35)$ & .614 & $4.29(2.27)$ & $4.29(2.13)$ & .000 & 0.01 \\
\hline Social Manipulation & $3.79(3.10)$ & $3.36(2.75)$ & .956 & $3.53(3.26)$ & $3.69(2.62)$ & .177 & 0.21 \\
\hline Attack on Property & $3.28(2.29)$ & $2.73(2.11)$ & 3.056 & $3.31(2.25)$ & $2.78(2.17)$ & 2.316 & 1.78 \\
\hline \multicolumn{8}{|l|}{${ }^{*} p<0.05$} \\
\hline \multicolumn{8}{|l|}{$* *_{p}^{*}<0.01$} \\
\hline \multicolumn{8}{|c|}{ df for developmental stage= 1} \\
\hline
\end{tabular}

Table 1 reveals that there is a significant gender difference in adolescents with respect to reactive aggression $(\mathrm{F}=4.61, \mathrm{p}<0.05)$ as well as proactive aggression $(\mathrm{F}=10.92, \mathrm{p}<0.01)$. As it is evident from the mean scores, boys $(M=13.31)$ have scored significantly higher than the girls $(M=11.65)$ with respect to reactive aggression. In other words, boys exhibited aggressive behaviors due to a perceived threat more than the girls. Also, boys $(M=7.36)$ have scored significantly higher than girls (4.91) with respect to proactive aggression. In other words, boys engage in aggressive goal oriented behaviors more than the girls. Theresults also revealed that there is a significant gender difference with respect to physical victimization $(\mathrm{F}=1.01, \mathrm{p}<0.01)$. As evident from the mean scores, the boys $(M=2.15)$ scored significantly higher than girls $(M=1.01)$. In other words, boys were inflicted with physically hurtful behaviors by their peers more than the girls.

Table 2 - Results of correlation between the dimensions of Attachment, Aggression and Victimization in middle adolescents $(n=111)$.

\begin{tabular}{lcccccccc}
\hline \multicolumn{1}{c}{ Variables } & $\begin{array}{c}\text { Maternal } \\
\text { Attachment }\end{array}$ & $\begin{array}{c}\text { Paternal } \\
\text { Attachment }\end{array}$ & $\begin{array}{c}\text { Peer- } \\
\text { Attachment }\end{array}$ & $\begin{array}{c}\text { Reactive } \\
\text { Aggression }\end{array}$ & $\begin{array}{c}\text { Proactive } \\
\text { Aggression }\end{array}$ & $\begin{array}{c}\text { Physical } \\
\text { Victimization }\end{array}$ & $\begin{array}{c}\text { Verbal- } \\
\text { Victimization }\end{array}$ & $\begin{array}{c}\text { Social } \\
\text { Manipulation }\end{array}$ \\
\hline Reactive Aggression & -.096 & .096 & $.261^{* *}$ & & & & \\
Proactive Aggression & -.126 & .046 & $.195^{*}$ & $.703^{* *}$ & & & & \\
Physical Victimization & -.054 & -.092 & -.138 & $.199^{*}$ & $.225^{*}$ & & & \\
Verbal Victimization & -.099 & .122 & .023 & $.440^{* *}$ & $.417^{* *}$ & $.373^{* *}$ & & \\
Social Manipulation & -.042 & -.160 & $-.287^{* *}$ & .127 & .116 & $.332^{* *}$ & $.371^{* *}$ & \\
Attack On Property & -.151 & -.011 & -.097 & $.413^{* *}$ & $.311^{* *}$ & $.307^{* *}$ & $.472^{* *}$ & $.282^{* *}$ \\
\hline$*(p<0.05)$ & & & & & & & & \\
$* *(p<0.01)$ & & & & & & & &
\end{tabular}

Table 2 reveals that there is a significant positive correlation between the domain of peer attachment and reactive aggression $(r=0.26, p<0.01)$ as well as proactive aggression $(r=0.19, p<0.05)$. In other words, the more the adolescents were perceived to be psychologically secure with the peers the more they engaged in aggressive behaviors which is the result of a perceived threat as well as behaviors used to reach a desired outcome. There is a significant positive correlation between the dimension of reactive aggression and physical victimization $(r=0.19, \mathrm{p}<0.05)$, verbal victimization $(\mathrm{r}=0.44, \mathrm{p}<0.01)$, attack on property $(\mathrm{r}=0.41, \mathrm{p}<0.01)$. In 
other words, the more the adolescents engaged in aggressive and hostile behaviors due to a perceived threat from the environment the more they experienced physically and verbally hurtful and more direct forms of peer victimization. Table 2 also indicates that there is a significant positive correlation between proactive aggression and physical victimization $(\mathrm{r}=0.22, \mathrm{p}<0.05)$, verbal victimization $(\mathrm{r}=0.41, \mathrm{p}<0.01)$ and attack on property $(\mathrm{r}=0.31, \mathrm{p}<0.01)$. In other words, the more the adolescents engaged in goal oriented aggressive behaviors the more they experienced hurtful behaviors inflicted by their peers. Table 2 also shows that there is a significant negative correlation between peer attachment and social manipulation $(r=-0.28, p<0.01)$. In other words the more the adolescents were perceived to be psychologically secure the less are they influenced and coerced by their peers.

Table 3-Results of correlation between the dimension of Attachment, Aggression and Victimization in late adolescents $(n=84)$

\begin{tabular}{|c|c|c|c|c|c|c|c|c|}
\hline Variables & $\begin{array}{c}\text { Maternal- } \\
\text { Attachment }\end{array}$ & $\begin{array}{l}\text { Paternal- } \\
\text { Attachment }\end{array}$ & $\begin{array}{c}\text { Peer- } \\
\text { Attchment } \\
\end{array}$ & $\begin{array}{c}\text { Reactive- } \\
\text { Aggression }\end{array}$ & $\begin{array}{l}\text { Proactive- } \\
\text { Aggression }\end{array}$ & $\begin{array}{c}\text { Physical- } \\
\text { Victimization }\end{array}$ & $\begin{array}{c}\text { Verbal- } \\
\text { Victimization }\end{array}$ & $\begin{array}{c}\text { Social } \\
\text { Manipulation }\end{array}$ \\
\hline Reactive-Aggression & .050 & .087 & -.021 & & & & & \\
\hline Proactive-Aggression & .026 & .030 & -.112 & $.635^{* *}$ & & & & \\
\hline Physical-Victimization & -.045 & -.024 & -.144 & .202 & $.264^{*}$ & & & \\
\hline Verbal-Victimization & .025 & .085 & .056 & $.336^{* *}$ & $.260^{*}$ & $.363^{* *}$ & & \\
\hline Social Manipulation & .038 & .068 & -.025 & $.289^{* *}$ & .174 & $.234^{*}$ & $.312^{* *}$ & \\
\hline Attack On Property & .028 & -.047 & -.050 & $.339^{* *}$ & $.301^{* *}$ & $.307^{* *}$ & $.441^{* *}$ & $.461^{* *}$ \\
\hline
\end{tabular}

Table 3 reveals that there is a significant positive correlation between reactive aggression and verbal victimization $(r=0.33, \mathrm{p}<0.01)$, social manipulation $(\mathrm{r}=0.28, \mathrm{p}<0.01)$ and attack on property $(\mathrm{r}=0.33, \mathrm{p}<0.01)$. In other words, the more the adolescents engaged in aggressive behaviors as a result of a perceived threat or a danger from the environment the more they were inflicted with verbally hurtful, manipulative and coercive behaviors by their peers. There is a significant positive correlation between proactive aggression and physical victimization $(r=0.26, p<0.05)$, verbal victimization $(r=0.26, p<0.05)$, attack on property $(r=0.30, p<0.01)$. In other words the more the adolescents engaged in goal oriented aggressive behaviors the more they experienced physically and verbally hurtful and more direct forms of peer victimization.

\section{DISCUSSION}

The objective of the current research was to determine if there was a difference between middle and late adolescent boys and girls with respect to attachment, aggression and victimization. The study also aimed to determine if there was a relationship between the same.

The findings of the present study revealed that boys experienced both reactive and proactive aggression more than the girls. Boys tend to respond to provocation with reactive aggression and indulge more in rough behaviors in order to be accepted by their peers, as friendship among boys is more power driven while girls prefer more intimate and dyadic interactions (Salmivalli et al., 1996; Boulton, 1999). According to Pulkkein (1996), individuals who displayed only proactive aggression are rare and is generally accompanied by reactive aggression as these two types of aggression are highly correlated.

The study also revealed that boys experience more physical victimization than girls. These findings can be supported by results of the study conducted by Sullivan, Farrell and Kliewer (2006), who concluded that boys experience more physical victimization whereas girls subject to relational victimization. .

The present study found that there is a significant correlation between peer attachment and the dimensions of reactive and proactive aggression in middle adolescents. This may be because a strong need for acceptance, belongingness and conformity in adolescence, lead these youngsters to exhibit aggressive behaviors as part of a group. A study conducted by Dodge and Coie (1987) support this finding. They found that reactive aggression was associated with a "hostile attribution bias" when deducing the intentions of a peer, whereas proactive aggression was associated with a more positive evaluation of aggression, especially in the context of a conflict with a peer. In a subsequent study by Dodge and Coie (1987), it was found that boys who were reactive 
aggressors were negatively viewed by their peers whereas proactive aggressors, even though sometimes rejected by their peers were perceived as having positive attributes such as good leadership qualities and sense of humor.

The study also found a significant negative correlation between the dimension of peer attachment and the dimension of social victimization. Teenagers seek autonomy from their parents spending more time with their peers (Prinstein, Boergers\&Vernberg, 2001) and forming groups which are "hierarchical" and are increasingly concerned about their popularity and status among these groups. In order to maintain dominion among these groups social manipulation may manifest itself. Social manipulation can be understood as covert or indirect acts of manipulation that inflict indirect harm and social damage (Mynard\& Joseph, 2000).

The study also reported a significant positive correlation between the dimension of reactive aggression and three dimensions of peer victimization namely physical victimization, verbal victimization and attack on property in middle adolescents. This could be due to the perception of the adolescents of the intensions of their peers as being hostile and threatening which in turn causes provocation and as a result of this provocation they may inflict physical and verbal harm. Not only do they inflict harm on their peers, they may also be on the receiving end of such hostile behaviors as they are viewed negatively by their peers. Reactive aggression is a 'hot blooded' and emotionally dysregulated type of aggression (Dodge \&Coie, 1987) eliciting negative reactions such as "peer rejection, low peer acceptance, lack of friends, and victimization" (Dodge et al., 1990; Perry, Perry, \& Kennedy, 1992; Schwartz et al., 1998).

The study also found that there is a significant positive correlation between the dimension of proactive aggression and physical victimization, verbal victimization and attack on property dimensions of peer victimization among middle adolescents. Even though adolescents are increasing concerned about their peers, by the time they reach middle adolescence their focus is directed towards themselves more than their peers. Raine et al., (2006) suggest that proactive aggression may be characterized by intrinsic motivation and be very salient to the initiator. Adolescent who exhibit proactive aggression and are subject to victimization can be categorized as proactive victims (Olweus, 1973), bully victims (Whitney \& Smith, 1993)or aggressive victims(Perry et al., 1988), as not only are the victims of hostile behaviors but are also a part of these aggressive groups. The findings indicate that there is a positive correlation between the dimensions of reactive aggression and verbal victimization, social manipulation and attack on property dimension among late adolescents. Havighurt (1972) in his developmental milestones for adolescents suggest that adolescents undergo intellectual and cognitive development, however the rate at which these abilities develop may not be the same for all individuals and may therefore result in a developmental difficulties. Previously conducted research suggests that reactive aggression can be associated with deficits in social processing and lack of inhibitory control (Crick \&Dodge 1996; Dodge \&Coei, 1987) and is associated with victimization (Schwartz et al., 1998)

The study also found a significant relationship between the dimension of proactive aggression and physical victimization, verbal victimization and attack on property. Havighurt(1972) suggests that by the time individuals reach late adolescence they develop a sense of personality. Proactive aggression can be linked to personality issues such as delinquency and anti-social behaviours (Raine et al., 2006)). Proactive aggression can also be linked to poor peer relations as they have a negative peer status(Dodge \&Coie, 1987) which may result in peer victimization.

\section{IMPLICATIONS}

The findings of the present study can be used to create awareness among parents, teachers and adolescents regarding the effects and consequences of manifestation of anger and effects of victimization. Research suggests that manifestation aggression is associated with internalizing symptoms such as anxiety, low self-esteem and externalizing symptoms such as delinquency and substance use. The findings can also be used to plan interventions to help adolescents develop nurture and maintain closer bonds with their peers and reduce incidences of aggression and victimization, as the quality of peer relations contributes to psychological adjustment of the adolescents (Parker \& Asher, 1987).

\section{REFERENCES}

[1] Aksel, E. S., \& Kaplan, B. (2013). ERGENLERDE BAĞLANMA VE SALDIRGANLIK DAVRANIŞLARI ARASINDAKİ İLIŞKINIIN İNCELENMESİ.Nesne-PsikolojiDergisi, (1), 20-49.

[2] Allen, J. P., \& Land, D. (1999).Attachment in adolescence. Handbook of attachment: Theory, research, and clinical applications, 319-335.

[3] Allen, J. P., Porter, M., McFarland, C., McElhaney, K. B., \& Marsh, P. (2007).The relation of attachment security to adolescents' paternal and peer relationships, depression, and externalizing behavior. Child development,78(4), 1222-1239. 
[4] Andreou, E. (2001). Bully/victim problems and their association with coping behaviour inconflictual peer interactions among school-aged children. Educational Psychology, 21(1),59-66. doi:10.1080/01443410020019830.

[5] Archer J, Coyne SM. An integrated review of indirect, relational and social aggression. Personality and Social Psychology Review. 2005;9(3):212-230.

[6] Armsden, G., Greenberg, M. T., Kailua, H. I. (1987) INVENTORY OF PARENT AND PEER ATTACHMENT (IPPA).

[7] Armsden, G.C., \& Greenberg, M.T. (1987). The inventory of parentand peer attachment: Individual differences and their relationship to psychological well-being in adolescence. Journal of Youth and Adolescence, 16, 427-454.

[8] Arnocky, S., \&Vaillancourt, T. (2011).A multi-informant longitudinal study on the relationship between aggression, peer victimization, and dating status in adolescence. Evolutionarypsychology: an international journal of evolutionary approaches to psychology and behavior, 10(2), 253-270.

[9] Barboza, G. E., Schiamberg, L. B., Oehmke, J., Korzeniewski,S. J., Post, L. A., and Heraux, C.G. (2009). Individual Characteristics and the Multiple Contexts of Adolescent Bullying: An Ecological Perspective. Journalof Youth Adolescence, 38, 101-121.

[10] Bellmore, A. D., Whitkow, M. T., Graham, S., \& Juvonen, J. (2004). Beyond the individual: The impact of ethnic context and classroom behavioral norms on victim's adjustment. Developmental Psychology, 40, 1159-1172. doi: 10.1037/0012-1649.40.6.1159.

[11] Benoit, D. (2004). Infant-parent attachment: Definition, types, antecedents, measurement and outcome. Paediatrics \& child health, 9(8), 541.

[12] Beran, T. (2009).Correlates of peer victimization and achievement: An exploratory model.Psychology in School, 46(4). 348-361. doi:10.1002/pits.20380

[13] Björkqvist KL, Lagerspetz KMJ, Kaukiainen A.1992. Do girls manipulate and boys fight? Developmentaltrends in regard to direct and indirectaggression. AggrBehav 18:117-127.

[14] Bowlby, J. (1969). Attachment.Vol. 1 of Attachment and Loss. New York: Basic Books.

[15] Bowlby, J. (1988). A secure base: Parent-child attachment and healthy human development. New York: Basic Book.

[16] Boulton, M. J. (1999). Concurrent and longitudinal relations between children's playgroundbehavior and social preference, victimization, and bullying. Child Development, 70, 944-954.

[17] Bretherton, I. (1992). The origins of attachment theory: John Bowlby and Mary Ainsworth. Developmental psychology, 28(5), 759.

[18] Bronfenbrenner, U. and Morris, P. (1998).The ecology of developmental process.The Handbook of ChildPsychology, 1, 993-1029.

[19] Buist, K. L., Dekovic, M., Meeus, V. H., ve van Aken, M. A. G. (2004). Attachment in adolescence: A social relations model analysis. Journal of Adolescent Research, 19(6), 826-850.

[20] Color, B., Egeland, B., Marvinney, D., Mangelsdorf, S., and Sroufe, LA (1989). Early childhood antecedents of aggression and passive withdrawal in earlyELEMENTARY SCHOOL. Journal of Personality, 57, 257-281.

[21] Crick NR, Bigbee MA. 1998. Relational and overtforms of peer-victimisation: a multiinformantapproach. J Consult ClinPsychol 66:337-347.

[22] Crick, N. R. \& Dodge, K. A. (1996).Social information-processing mechanisms in reactiveand proactive aggression.Child Development, 67, 993-1002.

[23] Crick NR, Grotpeter JK. Relational aggression, gender, and social-psychological adjustment. Child Development. 1995;66:710-722.

[24] Cullerton-Sen, C., Cassidy, A., Murray-Close, D., Cicchetti, D., Crick, N., \&Rogosch, F.(2008).Childhood maltreatment and development of relational and physical aggression:Developmental Psychology, 40, 1159-1172. doi: 10.1037/0012-1649.40.6.1159.

[25] Dinçel, E. (2006). Adolescence is a developmental assignments and psychological problems.

[26] Dodge, K. A. \&Coie, J. D. (1987). Social information-processing factors in reactive and proactiveaggression in children's playgroups.Journal of Personality and Social Psychology, 53,11461158.

[27] Espelage, D. L. (2002).Bullying in early adolescence:The role of the peer group. Champaign, IL: ERICClearinghouse on Elementary and Early ChildhoodEducation $\sim$ ERIC Document Reproduction Service No.ED471912

[28] Espelage, D. L. and Swearer, S. M. (2004).Bullying inAmerican schools: A social-ecological perspective onprevention and intervention. Mahwah, NJ: LawrenceErlbaum.

[29] Espelage, D. L. and Swearer, S. M. (2010). A social-ecologicalmodel for bullying prevention and intervention:Understanding the impact of adults in the social ecology of youngsters. In S.R. Jimerson, S. 
M. Swearer, and D. L.Espelage (Eds.), Handbook of bullying in schools: Aninternational perspective (pp. 61-72). New York:Routledge

[30] Estell, D., Farmer, T., Irvin, M., Crowther, A., Akos, P., \&Boudah, D. (2009). Students with exceptionalities and the peer group context of bullying and victimization in lateelementary school. Journal of Child and Family Studies, 18, 136-150. doi:10.1007/s10826-008-9214-1.

[31] Ferrer, B. M., Ruiz, D. M., Amador, L. V., \&Orford, J. (2011).School victimization among adolescents.An analysis from an ecological perspective. Psychosocial Intervention, 20(2), 149-160.

[32] Finnegan, R. A., Hodges, E., \& Perry, D. G. (1998). Victimization by peers: Associations with children's reports of mother-child interaction. Journal of Personality and Social Psychology, 75.

[33] Flaspohler, P. D., Elfstrom, J. L., Vandersee, K. L., Sink, H. E., \&Birchmeier, Z. (2009). Stand by me: The effects of peer and teacher support in mitigating the impact of bullying on quality of life. Psychology in Schools, 46, 636- 649.doi: 10.1002/pits.

[34] Gastic, B. (2008). School truancy and the disciplinary problems of bully victims. Educational Review, 60, 391-404. doi: 10.1080/00131910802393423

[35] Gibb, B. E., Abramson, L. Y., \& Alloy, L. B. (2004).Emotional maltreatment from parents, verbal peer victimization, and cognitive vulnerability to depression. Cognitive Therapy and Research, 28, 1-21.

[36] Gorssman, K. E., \& Grossman, K (1991).Attchmant quality as an organizer of emotional and behavioral responses in a longitudinal perspective.In C. M. Parkes, J. Stevenson-Hinde, \& P. Marris (Eds.), Attachment across the life-cycle.Tavistock, Uk: Routledge

[37] Havighurst, R.J. (1972). Developmental Tasks and Education. McKayHawker, SJ, Boulton MJ. 1997. Peer-victimisationand psychosocial adjustment: findings with aBritish sample. Paper presented at the BiennialMeeting of the Society of Research inChild Development. Washington, DC, April3, 1997.

[38] Hawker, D. S. J. \&Boulton, M. J. (2000). Twenty years' research on peer victimization andpsychosocial maladjustment: A meta-analytic review of cross-sectional studies. Journal ofChild Psychology and Psychiatry, 41, 441-455.

[39] Hazan, C., \& Shaver, P. R. (1994).Deeper into attachment theory.Psychological Inquiry, 5(1), 68-79.

[40] Jeynes, W. H. (2008). Effects of parental involvement on experiences of discrimination andbullying.Marriage \& Family Review, 43, 255-268. doi: 10.1080/01494920802072470.

[41] Karriker-Jaffe, K. J., Foshee, V. A., Ennett, S. T., \&Suchindran, C. (2008). The development of aggression during adolescence: Sex differences in trajectories of physical and social aggression among youth in rural areas.Journal of abnormal child psychology, 36(8), 1227-1236.

[42] Kempes, M., Matthys, W., De Vries, H., \& Van Engeland, H. (2005). Reactive and proactive aggression in children A review of theory, findings and the relevance for child and adolescent psychiatry. European child \& adolescent psychiatry, 14(1), 11-19.

[43] Klomek, A. B., Sourander, A., \& Gould M. (2010). The association of suicide and bullying in childhood to young adulthood: A review of cross-sectional and longitudinal research findings. Canadian Journal of Psychiatry, 55, 282-288.

[44] Kobak, R. (1999). The emotional dynamics of disruptions in attachment relationship: Implications for theory, research, and clinical intervention. In J. Cassidy \& P. Shaver International Online Journal of Educational Sciences, 2010, 2 (3), 719-737. (Eds.), Handbook of attachment; Theory research and, clinical applications. New York: Guilford.

[45] Kocayörük, E. (2010). Pathways to emotional well-being and adjustment in adolescence: The role of parent attachment and competence. International Online Journal of Educational Sciences, 2(3), 719-737.

[46] Kulaksızoğlu, A. (1998). Adolescent Psychology (Edition 1). Istanbul: Remzi Bookstore.

[47] Kuppens, S., Grietens, H., Onghena, P., \&Michiels, D. (2009). Associations between parental control and children's overt and relational aggression. British Journal of Developmental Psychology, 27, 607-623. doi: 10.1348/026151008X34SS91

[48] Lafrenier, P. and Sroufe, LA (1985). Profiles of peer competence in thepreschool: Interrelations between measures, influence of social ecology, andrelation to attachment history. Developmental Psychology, 17, 289-299.

[49] Lieberman, M., Doyle, A. B., \&Markiewicz, D. (1999). Developmental patterns in security of attachment to mother and father in late childhood and early adolescence: Associations with peer relations. Child development,70(1), 202-213.

[50] Limber, S. P. (2006). Peer victimization: The nature and prevalence of bullying among children and youth. In N. E. Dowd, D. G. Singer, and R. F. Wilson (Eds.), Handbookof children, culture and violence (pp. 313-332).Thousand Oaks, CA: Sage Publications.

[51] Loeber R, Hay D. Key issues in the development of aggression and violence from childhood to early adulthood. Annual Review of Psychology. 1997;48:371-410. [PubMed] 
[52] Lundh, L. G., Daukantaité, D., \&Wångby-Lundh, M. (2014).Direct and indirect aggression and victimization in adolescents-associations with the development of psychological difficulties. BMC psychology, 2(1), 43.

[53] Lynam, D. R., Hoyle, R. H., \& Newman, J. P. (2006). The perils of partialling cautionary tales from aggression and psychopathy. Assessment, 13(3), 328-341.

[54] Ma, C. Q., \& Huebner, E. S. (2008). Attachment relationships and adolescents life satisfaction: Some relationships matter more to girls than boys. Psychology in the Schools, 45(2), 177.

[55] Mayeux, L., \&Cillessen, A. H. N. (2008). It's not just being popular, it's knowing it, too: The role of selfperceptions of status in the associations between peer status andaggression. Social Development, 17, 871888. doi: 10.1111/j.1467-9507.2008.00474.x

[56] McLaughlin, K. A., Hatzenbuehler, M. L., \& Hilt, L. M. (2009).Emotion dysregulation as a mechanism linking peer victimization to internalizing symptoms in adolescents. Journal of Consulting and Clinical Psychology, 77, 894-904. doi: 10.1037/a0015760

[57] Mynard, H., \& Joseph, S. (2000). Development of the multidimensional peer-victimization scale. Aggressive Behavior, 26(2), 169-178.

[58] Olweus D. 1985.80,000 barn erinnblandet I mobbing.NorskSkoleblad 2:18-23.Olweus D. 1993. Bullying at school: what we knowand what we can do. Cambridge, MA: Blackwell.

[59] Parker, J. G., \& Asher, S. R. (1987). Peer relations and later personal adjustment: Are low-accepted children at risk?. Psychological bulletin,102(3), 357.

[60] Perry, BD (1996). Violence and childhood trauma: Understanding and respondingto the effects of violence on young children. Cleveland GundFoundationPublishers.

[61] Povedano, A., Cava, M. J., Monreal, M. C., Varela, R., \&Musitu, G. (2015).Victimization, loneliness, overt and relational violence at the school from a gender perspective. International Journal of Clinical and Health Psychology,15(1), 44-51.

[62] Prinstein, M. J., Boergers, J., Vernberg, E. M. 2001Overt and relational aggression in adolescence: Social psychological adjustment in aggressors and victims. Journal of Clinical Child Psychology, 30, 479- 491.

[63] Pulkkinen, L. (1996). Proactive and reactive aggression in early adolescence as precursorstoanti and prosocial behavior in young adults. Aggressive Behavior, 22, 241-257.

[64] Raine, A., Dodge, K., Loeber, R., Gatzke-Kopp, L., Lynam, D., Reynolds, C., ...\& Liu, J. (2006). The reactive-proactive aggression questionnaire: Differential correlates of reactive and proactive aggression in adolescent boys. Aggressive behavior, 32(2), 159.

[65] Ramos, R. C. (2013, February). Determinants of Aggression among Young Adolescents.In Proceedings of World Academy of Science, Engineering and Technology (No. 74, p. 596).World Academy of Science, Engineering and Technology (WASET).

[66] Redshaw, M., \& Martin, C. (2013). Babies, 'bonding'and ideas about parental 'attachment'. Journal of Reproductive and Infant Psychology, 31(3), 219-221.

[67] Salmivalli, C., Lagerspetz, K., Björkqvist, K., Österman, K., \&Kaukiainen, A. (1996).Bullying as a group process: Participant roles and their relations to social status within the group.Aggressive Behavior, 22, 115.

[68] Schwartz, D., McFayden-Ketchum, S. A., Dodge, K. A., Pettit, G. S., \& Bates, J. E. (1998).Peer group victimization as a predictor of children's behavior problems at home and in school.Development and Psychopathology, 10, 87-99.

[69] Smith PK, Cowie, H. Blades, M. (2003). Understanding children'sdevelopment (Fourth Edition). Oxford: Blackwell Publishing.

[70] Sroufe, L. A., Carlson, E. A., Levy, A. K., \&Egeland, B. (1999).Implications of attachment theory for developmental psychopathology. Development and psychopathology, 11(01), 1-13.

[71] Srouf, A., Egeland, B., \& Kreutzer, T. (1990). The fate of early experience following development change: Longitudinal approaches to individual adaptation in childhood. Child Development, 61, 13631373.

[72] Sullivan, T. N., Farrell, A. D., \&Kliewer, W. (2006). Peer victimization in early adolescence: Association between physical and relational victimization and drug use, aggression, and delinquent behaviors among urban middle school students. Development and psychopathology, 18(01), 119-137.

[73] Thijs, J., \&Verkuyten, M. (2008). Peer victimization and academic achievement in a multiethnic sample: The role of perceived academic self-efficacy. Journal of Educational Psychology, 100, 754-764. doi: $10.1037 / \mathrm{a} 0013155$

[74] Troy, M., and Sroufe, LA (1987). Victimization among preschoolers: Role ofattachment relationship history. Journal of the American Academy of Childand Adolescent Psychiatry, 26, 166-172.

[75] Tuvblad, C., Raine, A., Zheng, M., \& Baker, L. (2009). Genetic and environmentalstability differs in reactive and proactive aggression. Aggressive Behavior, 35, 437-452.doi: 10.1002/ab.20319 
[76] Whitney I, Smith PK. 1993. A survey of the nature andextent of bully/victim problems in junior/middleand secondary schools.Educ Res 35:3-25.

[77] Xie H, Cairns RB, Cairns BD. The development of social aggression and physical aggression: A narrative analysis of interpersonal conflicts. Aggressive Behavior. 2002;28:341-355.

[78] Xie H, Swift DJ, Cairns BD, Cairns RB. Aggressive behaviors in social interaction and developmental adaptation: A narrative analysis of interpersonal conflicts during early adolescence.Social Development. 2002;11(2):205-224.

[79] Yonas MA, O'Campo P, Burke JG, Peak G, Gielen AC. Urban youth violence: Do definitions and reasons for violence vary by gender? Journal of Urban Health: Bulletin of the New York Academy of Medicine. 2005;82(4):543-551.

[80] ZinatMotlagh, F., Ataee, M., Jalilian, F., MirzaeiAlavijeh, M., Aghaei, A., \&Shirazi, K. K. (2013).Predicting aggression among male adolescents: an application of the theory of planned behavior. Health promotion perspectives,3(2), 269. 